\title{
Article
}

\section{Invasive Populations of Emerald Ash Borer Agrilus planipennis Fairmaire, 1888 (Coleoptera: Buprestidae) in Saint Petersburg, Russia: a "Hitchhiker"?}

\author{
Andrey V. Selikhovkin ${ }^{1}$ https://orcid.org/0000-0003-4227-9647, Boris G. Popovichev ${ }^{1}$, Sergey A. Merkuryev 2,3 \\ https://orcid.org/0000-0002-1520-110X, Mark G. Volkovitsh ${ }^{4}$ https://orcid.org/0000-0003-2655-4784, Rimvys Vasaitis 5, \\ https://orcid.org/0000-0001-9349-4625 and Dmitry L. Musolin ${ }^{1}$ https://orcid.org/0000-0002-3913-3674 \\ 1 Department of Forest Protection, Wood Science and Game Management, Saint Petersburg State Forest \\ Technical University, Institutskiy Per. 5, 194021 Saint Petersburg, Russia; a.selikhovkin@mail.ru (A.V.S.); \\ b.g.popovichev@yandex.ru (B.G.P.); musolin@gmail.com (D.L.M.) \\ 2 Pushkov Institute of Terrestrial Magnetism of the Russian Academy of Sciences, Saint Petersburg Filial, \\ Universitetskaya Emb. 5, 199034 Saint Petersburg, Russian Federation; sam_hg@hotmail.com \\ 3 Saint Petersburg State University, Universitetskaya Emb., 7-9, 199034 Saint Petersburg, Russian Federation; \\ 4 Zoological Institute, Russian Academy of Sciences, Universitetskaya Emb., 1, 199034 Saint Petersburg, Rus- \\ sian Federation; polycest@zin.ru \\ 5 Department of Forest Mycology and Plant Pathology, Swedish University of Agricultural Sciences, SE-750 \\ Uppsala, Sweden; rimvys.vasaitis@slu.se \\ * Correspondence: rimvys.vasaitis@slu.se
}

\begin{abstract}
Emerald ash borer (EAB), Agrilus planipennis, is an invasive beetle of East Asian origin that in North America and Russia killed millions of ash trees (Fraxinus spp.). In September 2020, EAB was detected in Saint Petersburg, becoming resonant event for the metropolitan city. The aim of the present study was to investigate occurrence and ecology of EAB in Saint Petersburg. The presence of two distinct enclave populations of EAB was revealed, each of which has (very likely) been established by separate events of "hitchhiking" transport vehicles. Following the invasion, further spread of EAB in Saint Petersburg was slow and locally restricted, main explanation for which is climatic factor. Due to spread by "hitchhiking", the possibility of EAB further long-distance geographic spread of EAB in the Baltic Sea region (EU) is high, and not only by ground transport (120-130 km distance from EU borders), but also by ferries transporting cars (traditional means of transportation across the Baltic Sea). In certain cases, development of EAB on F. excelsior was more successful (stem portion colonized, larval densities, number of galleries, exit holes, viable larvae, emerged beetles) than in (adjacent) F. pennsylvanica trees. Observed relatively high EAB-sensitivity of $F$. excelsior therefore questions the efficacy and benefits of the currently ongoing selection and breeding projects against ash dieback (ADB), caused by Hymenoscyphus fraxineus. Inventory, mapping, and monitoring of surviving $F$. excelsior trees in areas infested by both $\mathrm{ADB}$ and $\mathrm{EAB}$ are necessary to acquire genetic resource for work on strategic long-term restoration of $F$. excelsior, tackling (inevitable) invasion of $\mathrm{EAB}$ to the EU.
\end{abstract}

Keywords: Emerald ash borer; Fraxinus spp.; forest pests; invasive populations; north-west Russia; Saint Petersburg; urban pests

\section{Introduction}

Ash (Fraxinus spp.) represents tree genus that historically has been, and until recent was widely used in various kinds of urban greenings of Saint Petersburg, where it was commonly planted along streets, alleys, parks, squares, inner gardens, etc., thus becoming one of the principal landscape components of the metropolitan city. In flora of the city 
and its suburbia ash is represented by two species - native European ash F. excelsior L. and introduced American green ash F. pennsylvanica March. F. pennsylvanica dominates in abovementioned greenings of general/public use comprising $6.7 \%$ of the area, while F. excelsior is a typical component of historical parks (such as Peterhof, Gatchina, Tsarskoye Selo, and others) and occasionally grows in mixed forests outside the city $[1,2]$. F. pennsylvanica in those parks is encountered only occasionally, as single trees.

Emerald ash borer, Agrilus planipennis Fairmaire, 1888 (Coleoptera: Buprestidae) $(\mathrm{EAB})$ is a lethal invasive beetle of East Asian origin that in North America killed untold millions of ash trees, resulting in ecological disaster [3]. In 2003, EAB was for the first time recorded in Moscow, shortly produced a massive outbreak in the city and killed most of the ash trees in parks and roadside plantings. Furthermore, the pest started spread from Moscow in all directions, and by 2020 the pest was recorded in 18 provinces of European Russia, towards the west approaching the border of Belarus and in the south-west invading eastern Ukraine [4,5]. In September 2020, EAB was detected in Saint Petersburg [5-7]. This became a resonant event for the city, famous with its architecture and historical parks.

In European Russia (but also in North America), formation of EAB invasive enclave populations, spatially/geographically separated from continuous EAB-infested areas, are not uncommon [5 and references therein]. Indeed, one example of these is currently observed invasion of EAB to Saint Petersburg. Previous investigations along the highway Moscow - Saint Petersburg showed its continuous population stretching westwards from Moscow to Tver [8]. However, no further expansion from Tver has been detected few years afterwards, while simultaneously reporting incidence and establishment of EAB in Saint Petersburg, a "jump" of approx. $520 \mathrm{~km}$ westwards from Tver [7]. To establish those enclave EAB populations, long-distance human-assisted transportation of EAB by cars and railway has been suggested, or, in other words, those vehicles must have been successfully "hitchhiked" by EAB [5,7].

Data on eventual further local spread of invasive EAB populations in newly invaded enclave geographic areas are not yet available, at least under European conditions. Another interesting aspect is that both EAB and its host tree (ash) in case of Saint Petersburg are geographically situated at their virtual northern limits (latitude of Saint Petersburg is about similar to that of Anchorage, Alaska), thus both species co-exist under certain climate-imposed stress conditions, plus the harsh environment of a large city. Moreover, little is known regarding the consequences of EAB infestation to F. excelsior, and in particular regarding its relative susceptibility to the pest as compared to a very EAB prone American ash species, as e.g., F. pennsylvanica. Although there are certain indications that in this respect $F$. excelsior might be more EAB-resistant e.g., along roadsides and city plantings [9,10], yet recent study in Moscow Province provided certain evidence that EAB is able for massive outbreaks causing significant damage also in forest stands [5]. The aim of the present study was to investigate population of EAB in Saint Petersburg City of Russia.

\section{Materials and Methods}

\subsection{Survey}

In order to check for eventual attacks of EAB to ash trees in Saint Petersburg area (Russia), during September 2020 - July 2021 we accomplished partial survey of urban plantings and city parks (Figure 1; localities \# 1-15, 22, and 24-28), and complete survey of Museum - Reserve Parks of Peterhof (Petrodvorets) and Gatchina (Figure 1; localities \# 16-21, 23, and 29). 


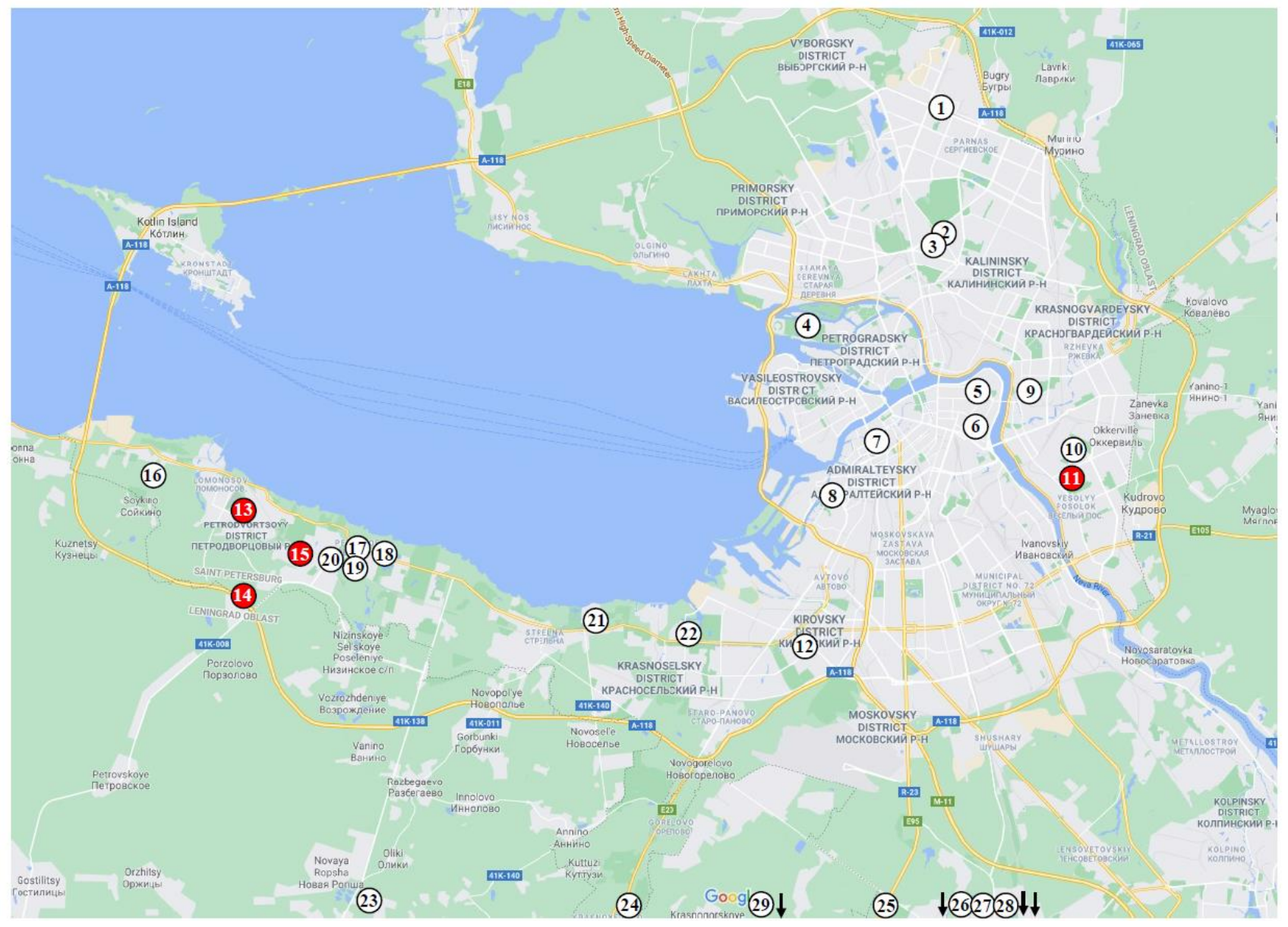

Figure 1. Locations in the territory of Saint Petersburg at which the survey for Emerald ash borer, Agrilus planipennis has been conducted in years 2020-2021. Location numbers as in the Table 1. Red circles indicate locations at which the beetle was detected, and white circles at which it was not detected. Arrows close to locations 26-29 indicate that those localities are situated more southwards (locations \# 26-28 approx. $5 \mathrm{~km}$; location \# $29-18 \mathrm{~km}$ ). Location \# 11 is situated at the Nevsky district, and locations \# 13-15 at the Petrodvortsovy district. Locations \# 17-21 are situated at the territory of State Museum - Reserve Park of Peterhof. Map is based on an image from (C) Google, 2021.

The surveys were done with collaboration and assistance by staff of the Department of Gardening and Park Management, Administration of Saint Petersburg City. During the survey, lower part of tree stems was visually inspected for incidence of bark loosening and cracks, and for the presence of characteristic exit holes of beetles and galleries of their larvae (Figures 2 and $3 a, b)$. Upper part of a stem and thick branches were inspected using binocular. Each tree on which attack of EAB was detected, was felled and examined in full detail. Moreover, we followed routine practices of the city Administration for removal of ash trees with various types of damage, constituting potential threat for public and property (Figure 3c). In such instances, each tree felled by them was examined in full detail. Species of ash included in the investigations of this work were F. excelsior and F. pennsylvanica. Numbers of trees examined, types of plantations, and their geographic coordinates are presented in the Table 1. 


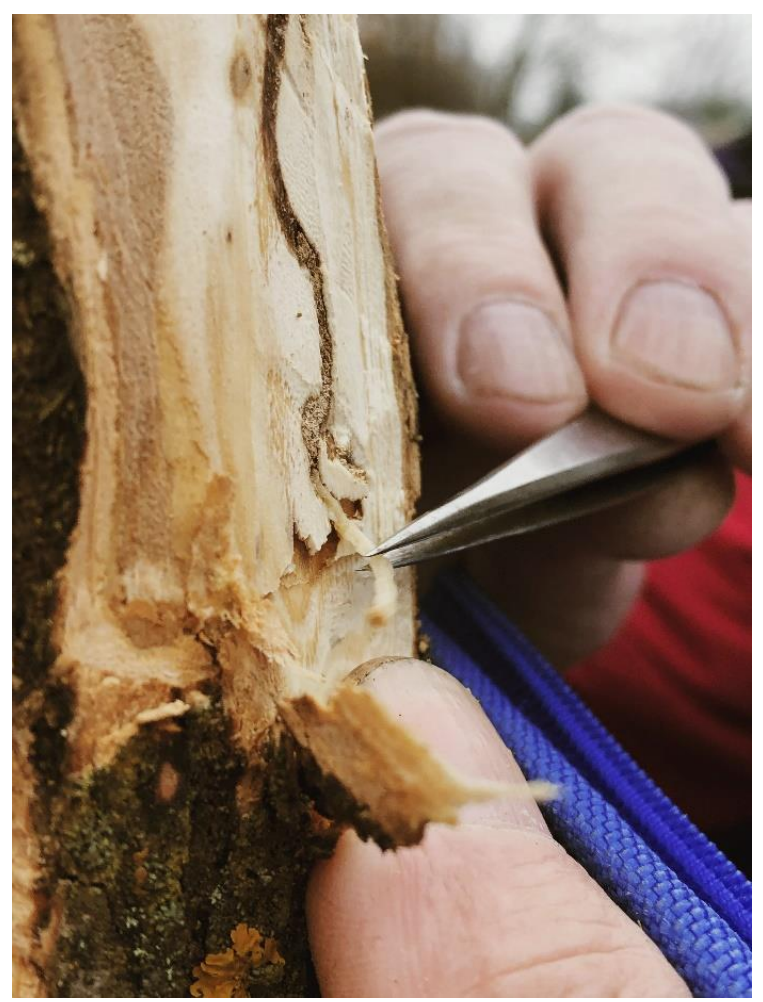

(a)

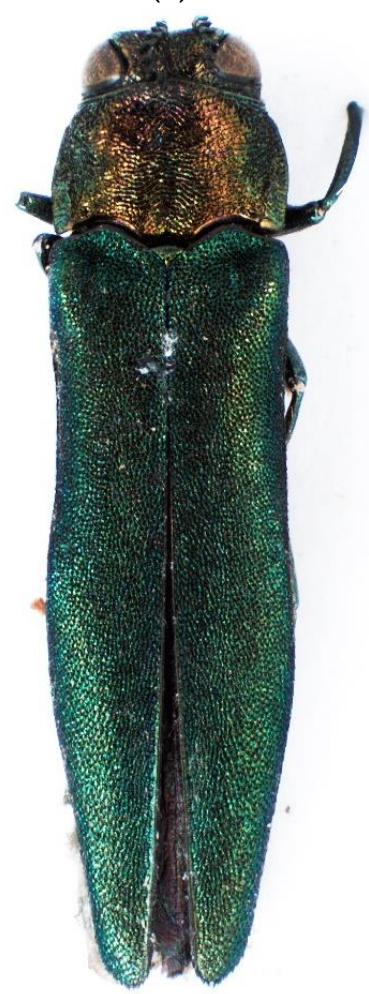

(c)

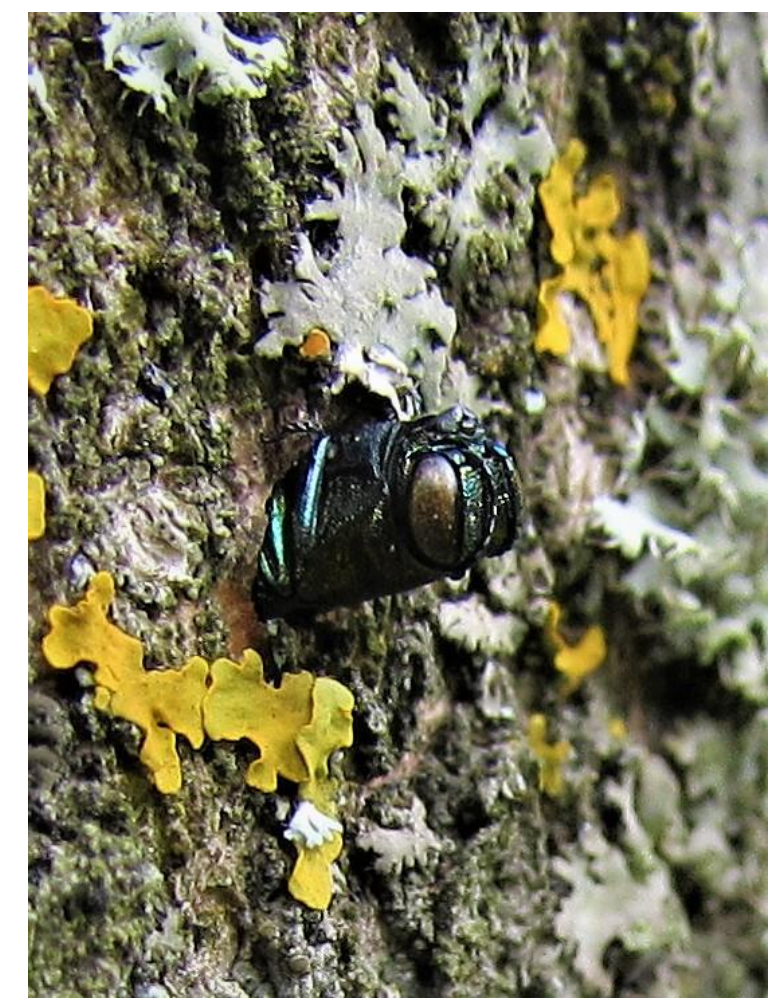

(b)

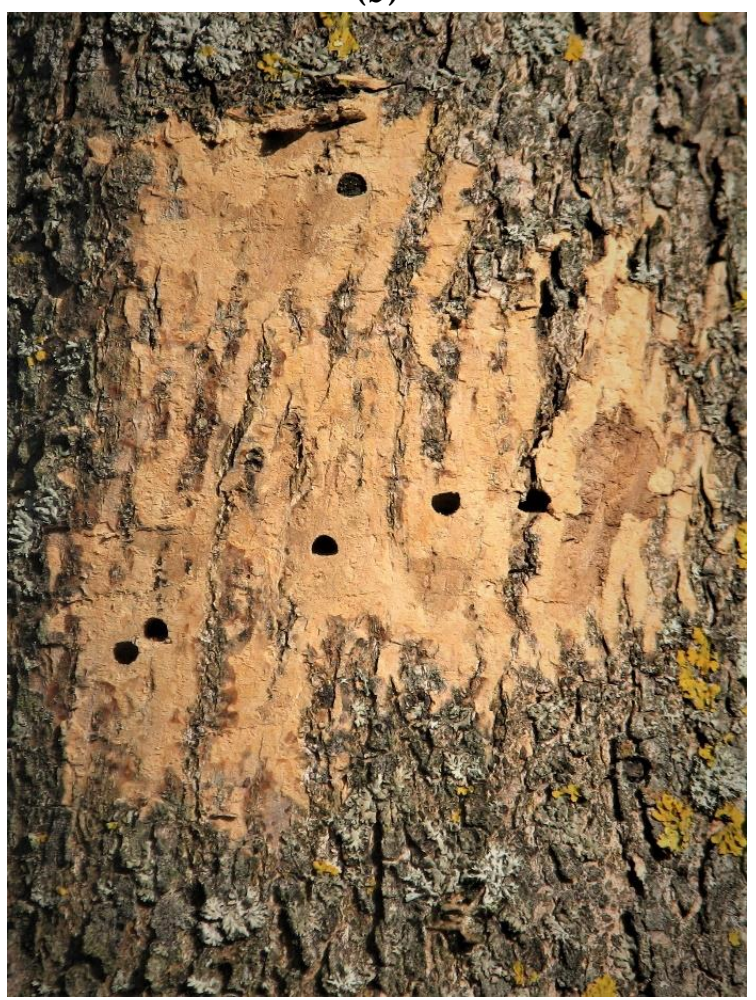

(d)

Figure 2. Emerald ash borer, Agrilus planipennis on ash trees in Saint Petersburg. (a) Larva being extracted from under the bark of Fraxinus pennsylvanica; (b) and (c) adult beetle, dead while emerging through an exit hole; (d) exit holes in bark of F. pennsylvanica. Photo by D.L. Musolin (a) and M.G. Volkovitsh (b-d). (Location \# 13.1; September-November 2020). 


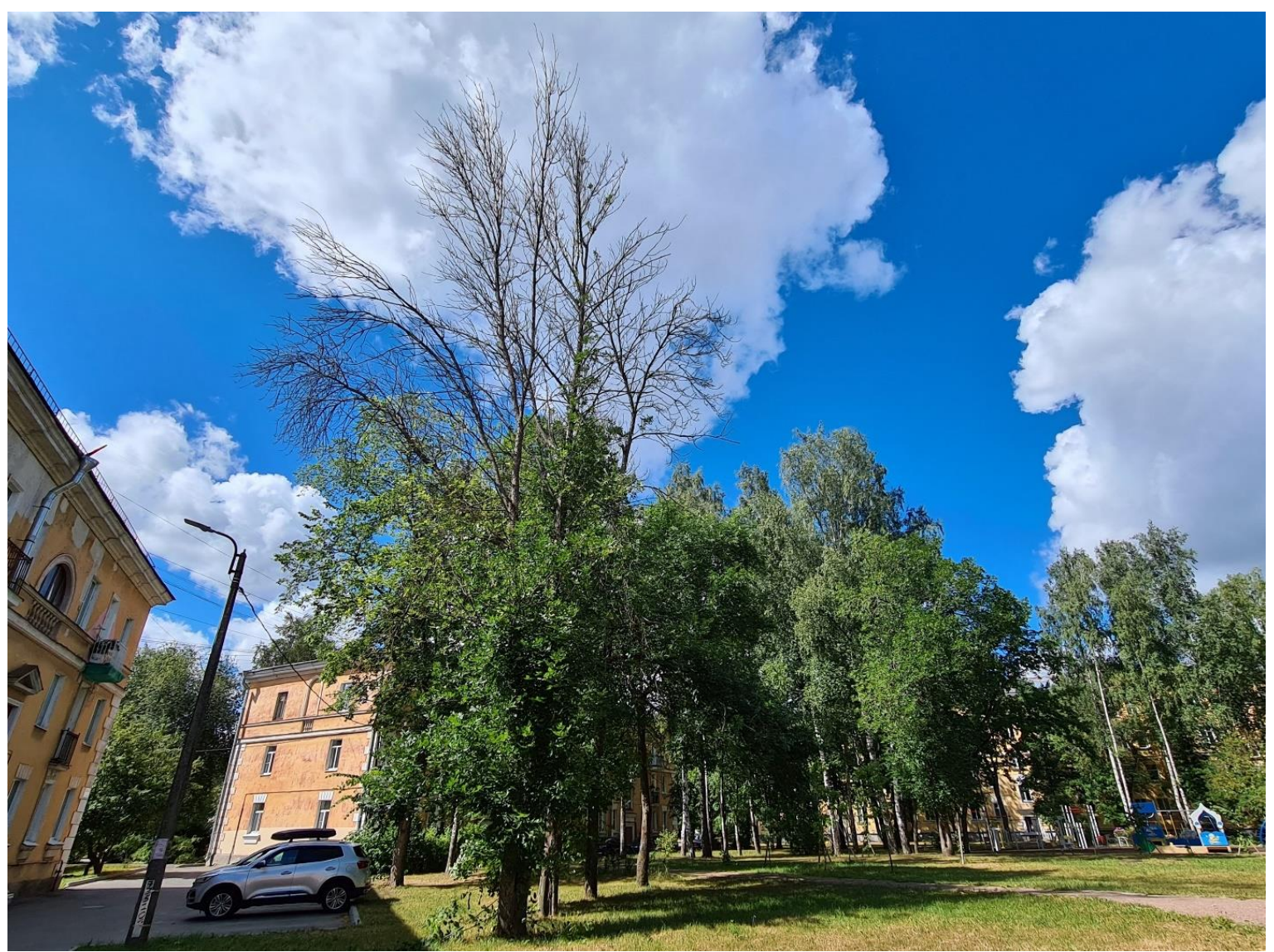

(a)

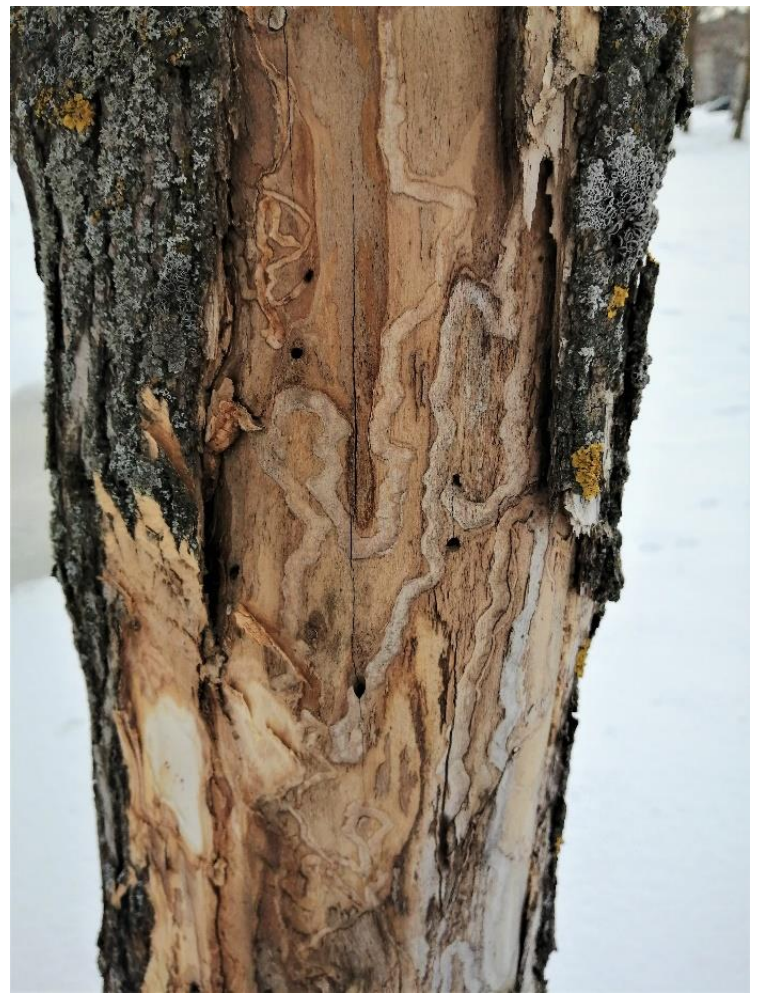

(b)

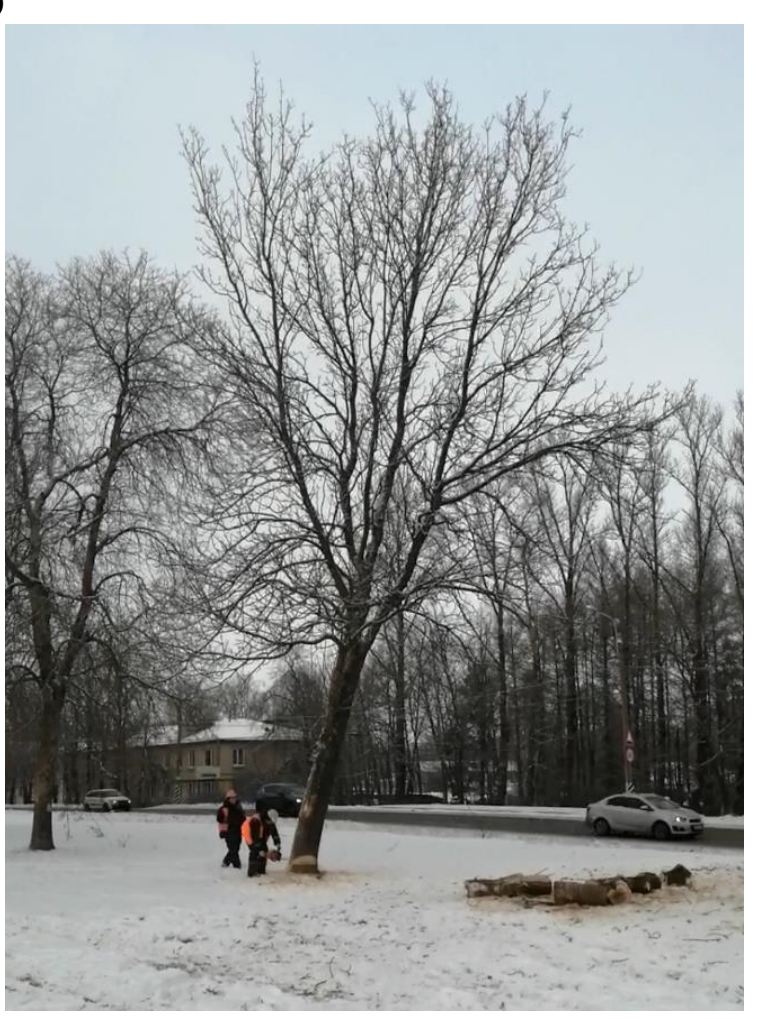

(c)

Figure 3. Emerald ash borer, Agrilus planipennis on ash trees in Saint Petersburg. (a) Dying infested F. pennsylvanica tree in a square at location \# 15.1 (July 2021); (b) old galleries of the beetle on dry-sided stem of F. pennsylvanica; (c) felling of infested F. pennsylvanica at the roadside, location \# 14 (January 2021). Photo by D.L. Musolin (a) and A.V. Selikhovkin (b, c). 
Table 1. Characteristics of localities (numbers as in Figure 1) in territory of Saint Petersburg in which during years 2020-2021 surveys have been done to identify eventual attacks by the Emerald ash borer (EAB), Agrilus planipennis to trees of Fraxinus excelsior and F. pennsylvanica. Localities in which EAB was detected $(\# 11,13,14$, and 15) are printed in bold.

\begin{tabular}{|c|c|c|c|c|c|}
\hline \multicolumn{2}{|r|}{ Locality of the survey } & \multirow[t]{2}{*}{ Plantation category } & \multicolumn{3}{|c|}{ No. of investigated ash trees } \\
\hline$\#$ & Coordinates & & $\begin{array}{l}\text { Visually from } \\
\text { the ground }\end{array}$ & $\begin{array}{c}\text { Of those, felled } \\
\text { and examined in } \\
\text { detail }\end{array}$ & $\begin{array}{c}\text { Attacked by } \\
\text { EAB }\end{array}$ \\
\hline
\end{tabular}

\section{PLANTINGS IN URBAN ENVIRONMENT}

Fraxinus excelsior

\begin{tabular}{clcccc}
3 & $59^{\circ} 59^{\prime} 34^{\prime \prime} \mathrm{N}, 30^{\circ} 20^{\prime} 33^{\prime \prime} \mathrm{E}$ & city park & 20 & 0 \\
\hline 4 & $59^{\circ} 58^{\prime} 16^{\prime \prime} \mathrm{N}, 30^{\circ} 14^{\prime} 48^{\prime \prime} \mathrm{E}$ & city park & 6 & 2 \\
\hline 5 & $59^{\circ} 56^{\prime} 41^{\prime \prime} \mathrm{N}, 30^{\circ} 22^{\prime} 49^{\prime \prime} \mathrm{E}$ & square (e.g., Figure 3a) & 1 & 1 \\
\hline 6 & $59^{\circ} 55^{\prime} 51^{\prime \prime} \mathrm{N}, 30^{\circ} 22^{\prime} 36^{\prime \prime} \mathrm{E}$ & square & 5 & 1 \\
\hline 7 & $59^{\circ} 54^{\prime} 49^{\prime \prime} \mathrm{N}, 30^{\circ} 17^{\prime} 17^{\prime \prime} \mathrm{E}$ & square & 15 & 0 \\
\hline 8 & $59^{\circ} 54^{\prime} 13^{\prime \prime} \mathrm{N}, 30^{\circ} 15^{\prime} 39^{\prime \prime} \mathrm{E}$ & city park & 6 & 0 \\
\hline 10 & $59^{\circ} 51^{\prime} 59^{\prime \prime} \mathrm{N}, 30^{\circ} 21^{\prime} 50^{\prime \prime} \mathrm{E}$ & city park & 15 & 0 \\
\hline 22 & $59^{\circ} 50^{\prime} 48^{\prime \prime} \mathrm{N}, 30^{\circ} 08^{\prime} 54^{\prime \prime} \mathrm{E}$ & city park & 20 & 0 \\
\hline 26 & $59^{\circ} 43^{\prime} 23^{\prime \prime} \mathrm{N}, 30^{\circ} 23^{\prime} 41^{\prime \prime} \mathrm{E}$ & city park & 30 & 4 \\
\hline 27 & $59^{\circ} 43^{\prime} 04^{\prime \prime} \mathrm{N}, 30^{\circ} 22^{\prime} 11^{\prime \prime} \mathrm{E}$ & city park & 25 & 0 \\
\hline 28 & $59^{\circ} 43^{\prime} 10^{\prime \prime} \mathrm{N}, 30^{\circ} 25^{\prime} 26^{\prime \prime} \mathrm{E}$ & alley & 147 & 0 \\
\hline
\end{tabular}

\section{Fraxinus pennsylvanica}

\begin{tabular}{clcccc}
1 & $60^{\circ} 03^{\prime} 32^{\prime \prime} \mathrm{N}, 30^{\circ} 20^{\prime} 59^{\prime \prime} \mathrm{E}$ & street & 10 & 0 & 0 \\
\hline 2 & $60^{\circ} 00^{\prime} 00^{\prime \prime} \mathrm{N}, 30^{\circ} 21^{\prime} 01^{\prime \prime} \mathrm{E}$ & street & 3 & 1 & 0 \\
\hline $9.1^{* *}$ & $59^{\circ} 55^{\prime} 35^{\prime \prime} \mathrm{N}, 30^{\circ} 24^{\prime} 26^{\prime \prime} \mathrm{E}$ & square & 16 & 1 \\
\hline 9.2 & $59^{\circ} 55^{\prime} 58^{\prime \prime} \mathrm{N}, 30^{\circ} 24^{\prime} 38^{\prime \prime} \mathrm{E}$ & city park & 4 & 1 \\
\hline 12 & $59^{\circ} 50^{\prime} 47^{\prime \prime} \mathrm{N}, 30^{\circ} 15^{\prime} 32^{\prime \prime} \mathrm{E}$ & street & 10 & 3 \\
\hline 24 & $59^{\circ} 43^{\prime} 56^{\prime \prime} \mathrm{N}, 30^{\circ} 05^{\prime} 32^{\prime \prime} \mathrm{E}$ & city park & 40 & 3 \\
\hline 25 & $59^{\circ} 43^{\prime} 50^{\prime \prime} \mathrm{N}, 30^{\circ} 17^{\prime} 35^{\prime \prime} \mathrm{E}$ & roadside (e.g., Figure 3c) & 84 & 0 \\
\hline & & Total & & 0 \\
\hline
\end{tabular}

\section{EAB invasion, Nevsky district}

\begin{tabular}{cccccc}
11.1 & $59^{\circ} 54^{\prime} 31^{\prime \prime} \mathrm{N}, 30^{\circ} 27^{\prime} 43^{\prime \prime} \mathrm{E}$ & city park $F . p .^{* * *}$ & 28 & 19 & 19 \\
\hline 11.2 & $59^{\circ} 54^{\prime} 38^{\prime \prime} \mathrm{N}, 30^{\circ} 27^{\prime} 59^{\prime \prime} \mathrm{E}$ & alley $F . e x .^{* * *}$ & 35 & 8 & 8 \\
\hline
\end{tabular}

\section{EAB invasion, Petrodvortsovy district}

\begin{tabular}{|c|c|c|c|c|c|}
\hline 13.1 & $59^{\circ} 54^{\prime} 08^{\prime \prime} \mathrm{N}, 2^{\circ} 49^{\prime} 02^{\prime \prime} \mathrm{E}$ & street $F . p$. & 63 & 63 & 63 \\
\hline 13.2 & $59^{\circ} 54^{\prime} 08^{\prime \prime} \mathrm{N}, 2^{\circ} 49^{\prime} 02^{\prime \prime} \mathrm{E}$ & street F. ex. & 3 & 1 & 1 \\
\hline 14 & $59^{\circ} 51^{\prime} 49^{\prime \prime} \mathrm{N}, 2^{\circ} 48^{\prime} 38^{\prime \prime} \mathrm{E}$ & roadside $F . p$. & 15 & 15 & 15 \\
\hline 15.1 & $59^{\circ} 53^{\prime} 01^{\prime \prime} \mathrm{N}, 2^{\circ} 52^{\prime} 00^{\prime \prime} \mathrm{E}$ & square $F . p$. & 20 & 0 & 4 \\
\hline \multirow[t]{2}{*}{15.2} & $59^{\circ} 53^{\prime} 36^{\prime \prime} \mathrm{N}, 2^{\circ} 51^{\prime} 54^{\prime \prime} \mathrm{E}$ & roadside $F . p$. & 12 & 0 & 1 \\
\hline & & Total F.p+F.ex. & $110+3$ & $78+1$ & $83+1$ \\
\hline
\end{tabular}

\section{STATE MUSEUM - RESERVE PARK OF PETERHOF}

\begin{tabular}{cccccc}
16 & $59^{\circ} 54^{\prime} 47^{\prime \prime} \mathrm{N}, 29^{\circ} 44^{\prime} 36^{\prime \prime} \mathrm{E}$ & F.ex. & 600 & 0 & 0 \\
\hline 17 & $59^{\circ} 53^{\prime} 12^{\prime \prime} \mathrm{N}, 29^{\circ} 54^{\prime} 30^{\prime \prime} \mathrm{E}$ & F. ex. & 275 & 4 & 0 \\
\hline 18 & $59^{\circ} 52^{\prime} 52^{\prime \prime} \mathrm{N}, 29^{\circ} 56^{\prime} 22^{\prime \prime} \mathrm{E}$ & F. ex. & 0 & 0
\end{tabular}




\begin{tabular}{|c|c|c|c|c|c|}
\hline \multicolumn{2}{|r|}{ Locality of the survey } & \multirow[t]{2}{*}{ Plantation category } & \multicolumn{3}{|c|}{ No. of investigated ash trees } \\
\hline$\#$ & Coordinates & & $\begin{array}{l}\text { Visually from } \\
\text { the ground }\end{array}$ & $\begin{array}{c}\text { Of those, felled } \\
\text { and examined in } \\
\text { detail }\end{array}$ & $\begin{array}{c}\text { Attacked by } \\
\text { EAB }\end{array}$ \\
\hline 19 & $59^{\circ} 52^{\prime} 37^{\prime \prime} \mathrm{N}, 29^{\circ} 54^{\prime} 29^{\prime \prime} \mathrm{E}$ & F.ex.+F.p. & $7+2$ & $1+0$ & 0 \\
\hline 20 & $59^{\circ} 53^{\prime} 33^{\prime \prime} \mathrm{N}, 29^{\circ} 51^{\prime} 59^{\prime \prime} \mathrm{E}$ & F.ex. & 25 & 0 & 0 \\
\hline \multirow[t]{2}{*}{21} & $59^{\circ} 51^{\prime} 13^{\prime \prime} \mathrm{N}, 30^{\circ} 02^{\prime} 46^{\prime \prime} \mathrm{E}$ & $F . e x .+F . p$. & $2+1$ & 0 & 0 \\
\hline & & Total F. ex. $+F . p$. & $2409+3$ & 5 & 0 \\
\hline \multicolumn{6}{|c|}{ STATE MUSEUM - RESERVE PARK OF GATCHINA } \\
\hline 23 & $59^{\circ} 43^{\prime} 24^{\prime \prime} \mathrm{N}, 2^{\circ} 51^{\prime} 31^{\prime \prime} \mathrm{E}$ & F.ex. & 300 & 12 & $0^{*}$ \\
\hline \multirow[t]{2}{*}{29} & $59^{\circ} 33^{\prime} 47^{\prime \prime} \mathrm{N}, 30^{\circ} 06^{\prime} 52^{\prime \prime} \mathrm{E}$ & F.ex. & 250 & 35 & $0^{*}$ \\
\hline & & Total & 550 & 47 & 0 \\
\hline
\end{tabular}

THROUGHOUT THE STUDY

Fraxinus excelsior, no. (\%)

3144

$71 \quad 9(0.3)$

Fraxinus pennsylvanica, no. (\%) 22

ALL, no. (\%)

3369

106

$102(45.3)$

* - galleries of Hylesinus crenatus and Hylesinus varius (Coleoptera: Curculionidae).

** - localities \# 9, 13, and 15 are divided into two, as each included two different categories of plantation.

*** F. p. - F. pennsylvanica.

**** F. ex. - F. excelsior.

\subsection{Dating of EAB infestations}

Dating of EAB infestations was accomplished for three categories of trees:

1) F. pennsylvanica in urban greenings of Petrodvortsovy district, 20-62 cm DBH, a total of 78 trees (localities \# 13.1 and 14);

2) F. pennsylvanica in Nevsky district, 16-24 cm DBH, a total of 19 trees planted year 1991 (locality \# 11.1); and

3) F. excelsior in Nevsky district, 11-12 cm DBH, a total of 35 trees planted year 2018 (locality \# 11.2) (Figure 1).

For trees from the first two categories the attempt was made to distinguish between "old" and "new" EAB attacks, and to estimate timing of those, while for trees from the third category (planted in 2018, thus two years previously to the investigation) only the timing for recent ("new") attacks could eventually be estimated. The basis for above estimates were visual examination of beetle galleries, exit holes, and eventual presence of larvae.

\subsection{Examination of sample trees}

Seven EAB-infested trees were subjected for individual detailed investigations, as sample trees. Those included four F. pennsylvanica 16-24 cm DBH (category 2; locality \# 11.1), and three F. excelsior 11-12 cm DBH (category 3; locality \# 11.2). They were felled, and on each of them, based on the presence of exit holes and galleries, portion of a stem colonized by EAB was estimated. Then, trees of the category 2 (planted 1991) were cut into stem sections $0.5 \mathrm{~m}$ - long, and trees of category 3 (planted 2018) into $1 \mathrm{~m}-$ long. For each section, bark surface area was estimated, as well as the numbers of EAB exit holes, individual galleries, and living larvae. For trees of category 2, based on external condition and parameters of the galleries, periods of infestation of different parts of stems were estimated. 


\section{Results}

The study included a total of 29 localities distributed throughout Saint Peterburg City and its suburbs (Figure 1). Studied localities represented different types of ash (Fraxinus spp.) plantings in urban environment, as city parks, squares (e.g., Figure 3a), alleys, streets, roadsides (e.g., Figure 3c), and two historical parks of Peterhof (Petrodvorets) and Gatchina. Totally, 185 F. excelsior and 222 F. pennsylvanica trees were visited and inspected in urban environment. F. excelsior almost exclusively was subject for the investigations in historical park of Peterhof (2409 trees and only 3 of F. pennsylvanica), and exclusively in Gatchina, where all 550 trees were F. excelsior. In summary, the study included 3144 trees of F. excelsior and 225 of F. pennsylvanica, what made it up to 3369 trees of both ash species (Table 1).

\subsection{Occurrence of EAB in Saint Petersburg}

EAB was detected in two distinct areas, one comprising locality \# 11 in Nevsky district, and another comprising cluster of localities \# 13,14, and 15 in Petrodvortsovy district (Figure 1). As evident from the Figure 1, these two districts are geographically separated from each other by the distance of approx. $40 \mathrm{~km}$, passing in straightforward manner partly through the Finnish Gulf and partly through the central part of the city, that includes 13 localities (\#5-10,12, and 17-22) in which EAB was not detected. Furthermore, EAB was also not detected in any other of 12 urban localities investigated, and neither in Peterhof nor Gatchina historical parks (Figure 1; Table 1).

Infested locality in the Nevsky district was comprised of two sub-localities - city park and alley. F. pennsylvanica was the only ash species represented in the city park, and among its 28 trees, 19 (67.9\%) were EAB-infested. The neighboring alley was composed exclusively by 35 trees of $F$. excelsior, 8 (22.9\%) of which were EAB-infested. Infested localities in urban Petrodvortsovy district represented plantings along roads and streets, and square (inner garden). Here, of a total of 110 of $F$. pennsylvanica trees examined, $83(75.5 \%)$ were infested by $\mathrm{EAB}$, while among examined three trees of $F$. excelsior, one was infested (Table 1). Examples of found dead EAB beetle, living larvae and EAB exit holes observed on stems are presented in the Figure 2.

In the Nevsky sub-locality \# 11.1, F. pennsylvanica trees growing in the park, were planted in year 1991, while the alley in sub-locality \# 11.2 consisted exclusively of F. excelsior trees planted in 2018. During investigation time (by 2021), F. pennsylvanica in locality \# 11.1 has reached stem DBH of $16-24 \mathrm{~cm}$. Among those trees, EAB-infested stems (towards southern direction) exhibited dry-sided symptoms, which were associated with relatively old galleries of EAB (Figure 3c). On the other hand, on stems of the same trees rather clear division was noted between those old and the galleries located higher up on the same stems that were fresh. Galleries of similar freshness were observed on 2018-planted neighboring \# 11.2 alley F. excelsior trees that were absent when the initial attacks took place on \# 11.1 park F. pennsylvanica. Furthermore, rather similar observations were made in Petrodvortsovy district (localities \# 13.2 and 14), where EAB-infested older 20-62 cm DBH trees exhibited dry-sided stems showing old galleries, but newly planted 8-12 cm DBH trees were recently EAB-attacked. Therefore, based on our experiences herewith we conclude that initial EAB attacks both at Nevsky and Petrodvortsovy districts outbreaks did occur in year 2015 and continued for some years thereafter, followed by a "new wave" outbreak that in both areas took place in 2019 on newly planted ash, thus next year after its outplanting.

\subsection{Ecology of a local EAB population in Nevsky area}


Table 2 roughly demonstrates approximate extent of colonization by EAB of four F. pennsylvanica sample stems in sub-locality \# 11.1 (planted 1991). In this respect, the situation observed in four investigated stems (in certain cases significantly) differ. Thus, after the 1st infestation wave of 2015-2018, EAB colonized approx. 2-4 m of lower stem part, during the 2nd wave the continued upwards colonization in trees no. 2 and 3 consisted of 1-2 m, yet in tree no. 3 it was $7 \mathrm{~m}$, while in tree no. 1 it was zero. Notably, in three F. excelsior trees (no. 5, 6, 7) in neighboring alley \# 11.2, subjected only to the 2nd wave of the infestation, 3-6 m long portions were colonized, making this about even to the extent observed in F. pennsylvanica trees no. 1, 2, and 3 after both waves. Absolute numbers of EAB larvae densities, galleries, exit holes, viable larvae and emerged beetles in each comparison were higher in F. excelsior (subjected only to 2nd infestation wave) than in F. pennsylvanica following both waves (Table 2).

Table 2. Infestations of Emerald ash borer, Agrilus planipennis on individual trees of Fraxinus pennsylvanica (planted year 1991; locality \# 11.1.) and F. excelsior (planted 2018; locality \# 11.2). The sites as shown in Figure 1 and Table 1 . Analysis of sample trees was conducted during January-April 2021.

\begin{tabular}{|c|c|c|c|c|c|c|c|c|c|}
\hline \multirow{2}{*}{$\begin{array}{l}\text { Tree no. } \\
\text { / years of } \\
\text { infestation }\end{array}$} & \multirow{2}{*}{$\begin{array}{c}\mathrm{DBH}, \\
\mathrm{cm}\end{array}$} & \multirow{2}{*}{$\begin{array}{c}\text { Height, } \\
\text { m }\end{array}$} & \multirow{2}{*}{$\begin{array}{l}\text { Colonised } \\
\text { stem } \\
\text { height, } \\
\text { min-max, } \\
\text { m }\end{array}$} & \multirow{2}{*}{$\begin{array}{c}\text { Larvae } \\
\text { density, } \\
\text { no. / bark } \\
\text { dm }^{2}\end{array}$} & \multicolumn{3}{|c|}{ No. per tree } & \multicolumn{2}{|c|}{ Percent per gallery } \\
\hline & & & & & Galleries & $\begin{array}{l}\text { Exit } \\
\text { holes }\end{array}$ & $\begin{array}{l}\text { Viable } \\
\text { larvae }\end{array}$ & $\begin{array}{c}\text { Emerged } \\
\text { beetles }\end{array}$ & $\begin{array}{c}\text { Emerged } \\
\text { beetles + } \\
\text { viable } \\
\text { larvae }\end{array}$ \\
\hline
\end{tabular}

\section{F. pennsylvanica}

\begin{tabular}{|c|c|c|c|c|c|c|c|c|c|}
\hline 1 / 2015-2018 & 16 & 8.5 & $0-4$ & 0.34 & 58 & 26 & $-^{*}$ & 44.8 & - \\
\hline 1 / 2019-2020 & & & +0 & 0 & 0 & 0 & 0 & - & 0 \\
\hline 2 / 2015-2018 & 16 & 10.2 & $0-4$ & 0.53 & 92 & 44 & - & 47.8 & - \\
\hline 2 / 2019-2020 & & & +1 & 0.29 & 50 & 10 & 12 & - & 44.0 \\
\hline 3 / 2015-2018 & 20 & 12.4 & $0-4$ & 0.25 & 64 & 48 & - & 75.0 & - \\
\hline 3 / 2019-2020 & & & +2 & 0.04 & 10 & 0 & 4 & - & 40.0 \\
\hline 4 / 2015-2018 & 21 & 9.3 & $0-2$ & 0.14 & 30 & 12 & - & 40.0 & - \\
\hline
\end{tabular}

\section{F. excelsior}

\begin{tabular}{|c|c|c|c|c|c|c|c|c|c|}
\hline 5 / 2019-2020 & 11 & 7.2 & $0-6$ & 0.29 & 43 & 8 & 26 & - & 79.1 \\
\hline 6 / 2019-2020 & 12 & 6.4 & $0-5$ & 0.71 & 156 & 37 & 75 & - & 71.8 \\
\hline 7 / 2019-2020 & 11 & 5.5 & $1-3$ & 0.77 & 60 & 4 & 3 & - & 11.7 \\
\hline
\end{tabular}

\section{Discussion}

The current study demonstrated the existence of two distinct outbreak areas of EAB in Saint Petersburg. Exact modes of entry of EAB to each of those are hard to define, yet most likely they are of different origin. Notably, in the Peterhof (Petrodvortsovy district) locality \# 14 infested F. pennsylvanica comprised tree row planted in the vicinity of a busy highway, while the Nevsky locality \# 11 (apart being situated in the opposite part of the city) is close to the river Neva which is commonly used as a water transport (shipment) corridor for wood to the Gulf of Finland. Introduction of EAB with plants for planting seems unlikely, as in both areas initial infestations are "old" (estimated start year 2015; coincides with the earlier suggestion [11]), and attacked trees are also old and large, and younger F. excelsior as e.g., in Nevsky district has been outplanted years after the initial outbreak. Thus, our work revealed the presence in Saint Petersburg of two distinct enclave EAB populations, each of which has (very likely) been established by separate events of "hitchhiking". This brings into the vision possibility of further long-distance geographic spread of EAB in the Baltic Sea region (thus EU) not only by ground transport 
(outbreaks located at 120-130 km distance, and well connected by highways and railroads to Estonian and Finnish borders), but also by ferries transporting cars and wood, especially keeping in mind that the passenger ferry transport infrastructure across Baltic Sea is indeed well developed.

However, following the invasion, further spread of EAB in Saint Petersburg was slow and locally restricted. One explanation for this can be low connectivity of Fraxinus plantings and highly urbanized environment of the city. Moreover, our study has demonstrated that EAB in Saint Peterburg has a two-year generation. Another indication for low suitability of Saint Petersburg area for development of EAB populations is the fact that none of the F. pennsylvanica trees attacked during its 1st wave in 2015-2018 has been killed, thus surviving up to the 2nd wave of 2019-2020. The most likely explanation for the restricted EAB spread is climatic factor, in particular low winter temperatures.

Absolute annual minimal temperatures below $-30^{\circ} \mathrm{C}$ are seemingly critical for the survival of $\mathrm{EAB}$ population, and isotherm of absolute minimum of $-34^{\circ} \mathrm{C}$ is apparently the climatic boundary for the area of EAB distribution [5,12]. In Saint Petersburg, despite the generally continuous trend of climate warming, such critically low temperatures were observed in the last century (e.g., in 1987), yet also during 2000s absolute yearly minimum at several instances has decreased to almost $-30^{\circ} \mathrm{C}$ (Figure 4). In year 2016, absolute minimal temperature decreased to nearly $-25^{\circ} \mathrm{C}$ (Figure 4 ). In year 2017, the sum of effective temperatures (calculated above $10^{\circ} \mathrm{C}$; [13]), at which presumably the development of EAB occurs, has sharply decreased (Figure 5). The data acquired during the present study indicate that during initial stages of the Saint Petersburg outbreak (years 2015-2017), EAB actively explored its food resources of ash, but following low temperatures of 2016-2017 (Figures 4 and 5) the expansion has been slowed down. In such case thick bark, under which larvae develop, could serve as an extra barrier of protection against low temperatures, and as a matter of fact, the lower part of the stems is where the development of EAB larvae has been successfully completed (Table 2). This could have also somehow slowed down further expansion of the pest.

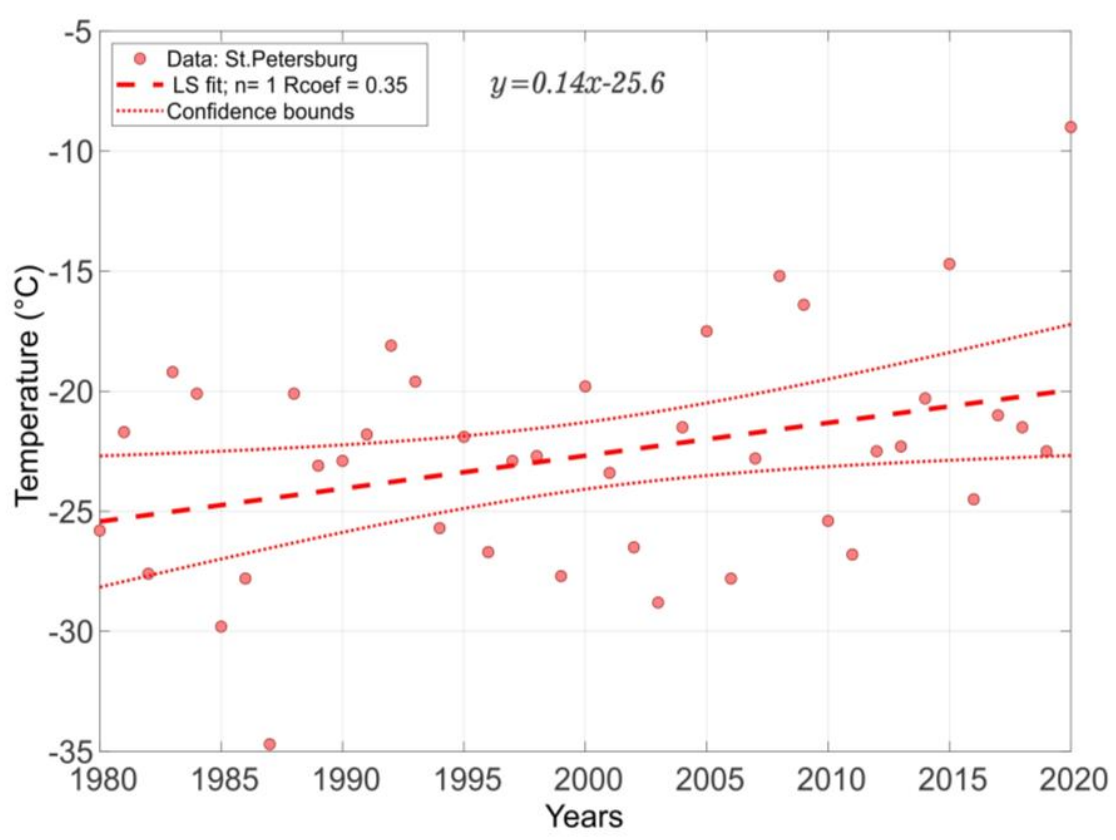

Figure 4. Absolute minimal temperatures in Saint Petersburg during 1980-2020. Red circles, measured values; dashed line, the line of regression; dotted lines, confidence interval. Rcoef - correlation coefficient. Formula of linear regression is shown in the upper part of the figure. Data from [14]. 


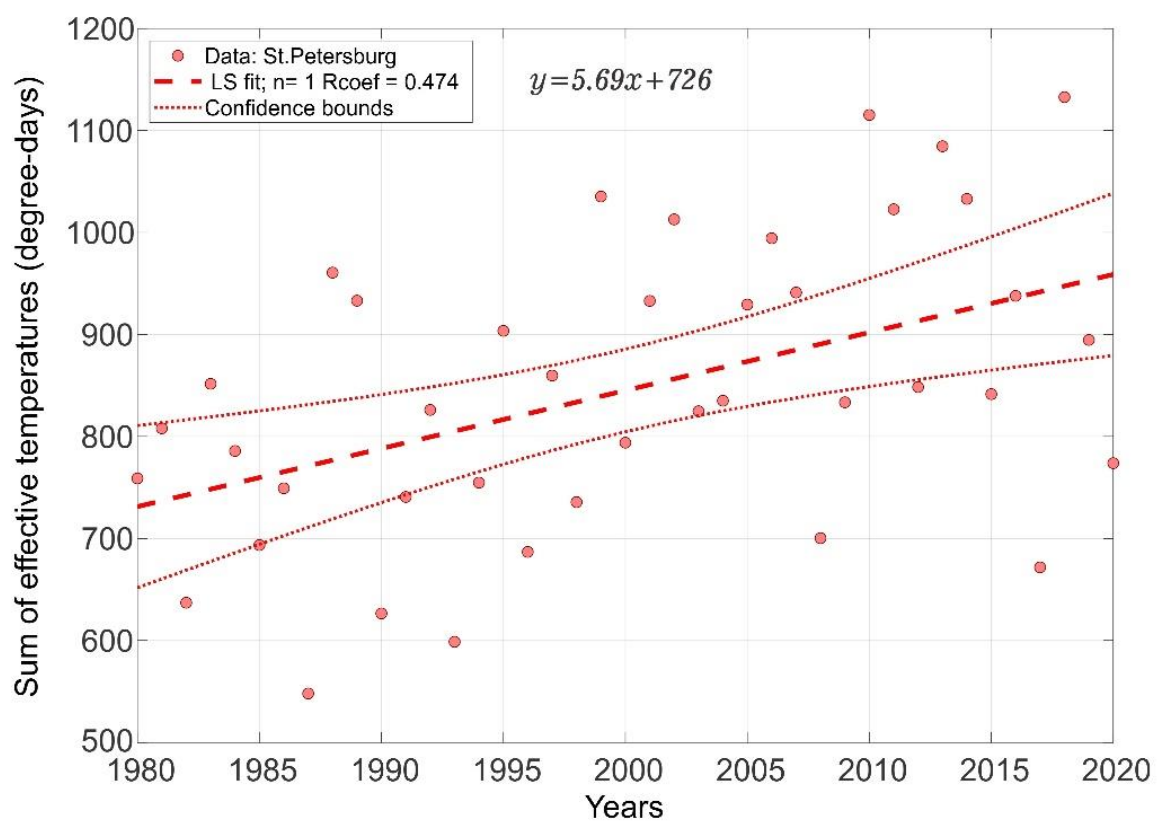

Figure 5. Dynamics of the sum of effective temperatures in Saint Petersburg during growing seasons (May-September) in 1980-2020 (calculated above the lower developmental threshold of $10^{\circ} \mathrm{C}$; [13]). Red circles, calculated values; dashed line, the line of regression; dotted lines, confidence interval. Rcoef - correlation coefficient. Formula of linear regression is shown in the upper part of the figure. Data from [14].

The possibility cannot be excluded that EAB could exhibit more enhanced establishment and spread upon its eventual arrival to Helsinki, Tallinn or Stockholm, that, although are the seaports situated at the similar northern latitudes, yet with more maritime, thus milder climate. On the other hand, it is hard to extrapolate and interpret our results on a larger geographic scale as in more southern areas situation will definitely differ, climate being more suitable for the pest.

Moreover, observations of the present study indicate the importance also of microclimatic conditions for attacks and subsequent development of EAB. Notably, all infested trees were growing in open spaces, as roadsides, squares, and streets, their stems partly exposed to sun. In Petrodvortsovy district, for example, out of 113 ash trees examined (although mostly F. pennsylvanica), 84 (74.3\%) were attacked by EAB, while in adjacent Reserve Park (mostly resembling city forest environment), none of 2409 (F. excelsior) was attacked (Table 1). Similar to that, at the Nevsky district, "shadowy" situated F. pennsylvanica has not been attacked either. Consequently, it is reasonable to assume that cold winters of 2016 and 2017 (Figure 4) were likely the principal reason that slowed down the development of EAB outbreak in Saint Petersburg.

Another important message sent by this work is that it presents (albeit scarce and fragmented) data demonstrating that at least in certain cases $F$. excelsior might be even more prone to EAB attacks than F. pennsylvanica, somehow contradicting few previous observations [4,15]. This is despite the fact that, e.g., at the locality \# 11 (Nevsky district), 19 out of $28(67.9 \%)$ 16-24 cm DBH F. pennsylvanica (planted 1991) were attacked by the pest, while among 35 more recently planted 8-12 cm DBH F. excelsior (planted 2018), only $8(22.9 \%)$ were attacked (Table 1). But here F. pennsylvanica has been exposed for EAB for about 3 years longer than F. excelsior. Notably, Table 2 demonstrates that numbers of EAB larvae densities, galleries, exit holes, viable larvae, and emerged beetles in each comparison were higher in F. excelsior than in F. pennsylvanica. As relatively large trees of F. excelsior have been planted relatively recently prior the attacks, such predisposition towards the pest could be probably explained by post-planting stress of a plant. Yet the current work presents the first available numerical/quantitative data documenting attacks by EAB to $F$. excelsior. It also demonstrates that in certain cases, following the attack 
(e.g. due to tree exposure to sun) development of EAB in F. excelsior might be more successful than that observed in (adjacent) F. pennsylvanica.

Since mid-2000s, severe ash dieback (ADB) is being observed in most European countries. The causal agent of ADB is the invasive alien fungus Hymenoscyphus fraxineus. The disease results in massive Fraxinus spp. mortality, threatening the existence of this tree species on a continental scale [16]. Yet, there is evidence that a proportion of European F. excelsior individuals across populations exhibits certain tolerance/resistance to $\mathrm{ADB}$, providing the basis for future selection, breeding and propagation $[17,18]$. However, the proportion showing high resistance to ADB is low, estimated in a range between $1 \%$ and $5 \%$ of individuals $[10,19,20]$. Consequently, ex situ conservation and resistance breeding programs have been initiated in many European countries, providing a promising perspective to mitigate the damaging effects of ADB in the long-term. However, on a large scale, EAB infestation combined with ADB infection is expected to be more lethal than either of them alone [19]. This brings the question on how effective and beneficial those (expensive and laborious) current selection and breeding programs against ADB will be, and to which extent those will contribute to restoration of native European ash populations on the long-term basis, tackling (the inevitable) invasion of EAB to the EU.

In this respect, ash trees that have been subjected to infestations both by ADB and EAB could have a certain potential for strategic solution. Naturally, F. excelsior trees planted at the locality \# 11.2 have been previously subjected also for ADB infection pressure (airborne spores) during for at least a decade (as all ash around the Baltic Sea region), and apparently were ADB-symptomless for being subsequently replanted in an urban alley. Therefore, those 27 F. excelsior trees that survived (or were not attractive) to EAB attacks (Table 2; location \# 11.2) constitute subject for further monitoring and eventual propagation, for which current work apparently represents the starting point. Moreover, similar investigations should be initiated on a large scale in EAB invaded areas in Russia and eastern Ukraine, creating databases of F. excelsior, comprising to date unique genetic resource (e.g., seed banks) for the whole Europe.

\section{Conclusions}

1. Present work has revealed the presence in Saint Petersburg of two distinct enclave populations of Emerald ash borer (Agrilus planipennis, EAB), each of which has (very likely) been established by separate events of "hitchhiking" of transport vehicles.

2. Following the invasion, further spread of EAB in Saint Petersburg was slow and locally restricted, main explanation for which is climatic factor, yet the invasion of the pest further westwards to the EU is highly possible.

3. In certain cases, EAB exhibits more successful development in Fraxinus excelsior than in (adjacent) F. pennsylvanica.

4. Efficacy and benefits of currently ongoing European ash selection and breeding projects against ash dieback (Hymenoscyphus fraxineus, ADB) are under the question.

5. Inventory, mapping, and monitoring of surviving ash trees in areas infested both by $\mathrm{ADB}$ and $\mathrm{EAB}$ is necessary to acquire genetic resource for work on strategic long-term restoration of F. excelsior, tackling (the inevitable) invasion of EAB to the EU.

Author Contributions: Conceptualization, A.V.S., D.L.M., and R.V.; methodology, A.V.S., D.L.M.; field work, A.V.S., B.G.P., M.G.V., and D.L.M.; formal analysis, D.L.M., S.A.M., and A.V.S.; writing-original draft preparation, A.V.S., R.V. and D.L.M.; writing - review and editing, A.V.S., R.V., B.G.P., M.G.V., and A.S.M.; visualization, A.V.S., S.A.M., M.G.V., and D.L.M.; supervision, D.L.M.; project administration, D.L.M.; funding acquisition, A.V.S., D.L.M., and R.V. All authors have read and agreed to the published version of the manuscript.

Funding: The research was funded by the Russian Science Foundation (data collection in 2021: project № 21-16-00065; A.V.S.; data analysis: project № 21-16-00050; D.L.M.). The study by M.G.V. (data collection in 2020, species identification, and MS editing) was undertaken within the framework of the State Project no. AAAA-A19-119020690082-8. The study by R.V. was funded by FORMAS, a Swedish Research Council for Sustainable Development. 
Data Availability Statement: Data are available upon email request to the corresponding author.

Acknowledgments: We sincerely acknowledge Dr. D.V. Suslov (Saint Petersburg State University), Mr. N.A. Mamaev, Mr. D.S. Glebov, Ms. M.B. Martitova, and Mr. G.S. Danilov (all - Saint Petersburg State Forest Technical University) for assistance in the field data collection.

Conflicts of Interest: The authors declare no conflict of interest. The funders had no role in the design of the study; in the collection, analyses, or interpretation of data; in the writing of the manuscript, or in the decision to publish the results.

\section{References}

1. Fyodorova, N.B. Trees and shrubs in Saint Petersburg and monitoring of their health status. Moscow State Forest University Bulletin - Lesnoi Vestnik 2009, 5, 202-206. (in Russian)

2. Fyodorova, N.B.; Osypov, D.V.; Grigoriev A.S. Results of monitoring of communal trees and shrubs in Saint Petersburg in 2007. In: Environmental protection, nature management and environmental safety in Saint Petersburg in 2007. Sesame-Print: Saint Petersburg, Russia, 2008, pp. 347-355. (in Russian)

3. Herms, D.A.; McCullough, D.G. Emerald ash borer invasion of North America: History, biology, ecology, impacts, and management. Ann. Rev. Entomol. 2014, 59, 13-30. (DOI: 10.1146/annurev-ento-011613-162051)

4. Orlova-Bienkowskaja, M.J.; Drogvalenko, A.N.; Zabaluev, I.A.; Sazhnev, A.S.; Peregudova, E.Y.; Mazurov, S.G.; Komarov, E.V.; Struchaev, V.V.; Martynov, V.V.; Nikulina, T.V.; Bieńkowski A.O. Current range of Agrilus planipennis Fairmaire, an alien pest of ash trees, in European Russia and Ukraine. Annals of Forest Science 2020, 77, 1-14. (DOI: 10.1007/s13595-020-0930-z)

5. Volkovitsh, M.G.; Bieńkowski, A.O.; Orlova-Bienkowskaja, M.J. Emerald ash borer approaches the borders of the European union and Kazakhstan and is confirmed to infest European ash. Forests 2021, 12, 691. (DOI: 10.3390/ f12060691)

6. Volkovitsh, M.G.; Suslov, D.V. The first record of the emerald ash borer, Agrilus planipennis Fairmaire (Coleoptera: Buprestidae), in Saint Petersburg signals a real threat to the palace and park ensembles of Peterhof and Oranienbaum. In Dendrobiotic Invertebrates and Fungi and their Role in Forest Ecosystems. The Kataev Memorial Readings - XI. Proceedings of the All-Russia Conference with International Participation; Musolin, D.L., Kirichenko, N.I., Selikhovkin, A.V., Eds.; Saint Petersburg State Forest Technical University: Saint Petersburg, Russia, 2020; pp. 121-122. (DOI: 10.21266/SPBFTU.2020.KATAEV)

7. Musolin, D.L.; Selikhovkin, A.V.; Peregudova, E.Y.; Popovichev, B.G.; Mandelshtam, M.Y.; Baranchikov, Y.N.; Vasaitis, R. North-westward expansion of the invasive range of emerald ash borer, Agrilus planipennis Fairmaire (Coleoptera: Buprestidae) towards the EU: From Moscow to Saint Petersburg. Forests. 2021, 12, 502. (DOI: 10.3390/f12040502)

8. Selikhovkin, A.V.; Popovichev, B.G.; Mandelshtam, M.Yu.; Vasaitis, R.; Musolin, D.L. The frontline of invasion: the current northern limit of the invasive range of Emerald ash borer, Agrilus planipennis Fairmaire (Coleoptera: Buprestidae), in European $\begin{array}{llllll}\text { Russia. } & \text { Baltic } & \text { Forestry } & 23 & (1) & 309-315\end{array}$ https://www.balticforestry.mi.lt/bf/index.php?option=com_content\&view=article\&catid=14\&id=482

9. Baranchikov, Yu.N.; Seraya, L.G.; Grinash, M.N. All European ash species are susceptible to emerald ash borer Agrilus planipennis Fairmaire (Coleoptera: Buprestidae) - a Far Eastern invader. Siberian Forest Journal 2014, 6, 80-85. (in Russian with English summary).

10. Musolin, D.L.; Selikhovkin, A.V.; Shabunin, D.A.; Zviagintsev, V.B.; Baranchikov, Y.N. Between ash dieback and emerald ash borer: Two Asian invaders in Russia and the future of ash in Europe. Baltic Forestry 2017, 23, 309-315. Available online: https://www.balticforestry.mi.lt/bf/PDF_Articles/2017-23\%5B1\%5D/Baltic\%20Forestry\%202017.1_316-333.pdf (accessed on 31 August 2021).

11. Baranchikov, Y.N. Dating of the beginning of the Agrilus planipennis Fairmaire (Coleoptera: Buprestidae) invasion to St. Petersburg using Internet technology. In Dendrobiotic Invertebrates and Fungi and their Role in Forest Ecosystems. The Kataev Memorial Readings - XI. Proceedings of the All-Russia Conference with International Participation; Musolin, D.L., Kirichenko, N.I., Selikhovkin, A.V., Eds.; Saint Petersburg State Forest Technical University: Saint Petersburg, Russia, 2020; pp. 70-71. (DOI: 10.21266/SPBFTU.2020.KATAEV)

12. Orlova-Bienkowskaja, M.J.; Bieńkowski, A.O. Minimum winter temperature as a limiting factor of the potential spread of Agrilus planipennis, an alien pest of ash trees, in Europe. Insects 2020, 11, 258. (DOI: 10.3390/insects11040258)

13. Brown-Rytlewski, D.; Wilson, M.A. Tracking the emergence of emerald ash borer adults. In Emerald ash borer research and technology development meeting; Mastro, V., Reardon, R., Eds.; USDA Forest Service publication FHTET-2004-15. 2004, pp. 13-14.

14. Specialized datasets for climatic studies. Available online: http://www.aisori-m.meteo.ru (accessed on 31 August 2021).

15. Baranchikov, Y.; Mozolevskaya, E.; Yurchenko, G.; Kenis, M. Occurrence of the emerald ash borer, Agrilus planipennis in Russia and its potential impact on European forestry. EPPO Bulletin 2008, 38, 233-238.

16. Vasaitis, R.; Enderle, R. (Eds.) Dieback of European Ash (Fraxinus spp.) - Consequences and Guidelines for Sustainable Management; Swedish University of Agricultural Sciences: Uppsala, Sweden, 2017; 320 p. Available online: http://www.slu.se/globalassets/ew/org/inst/mykopat/forskning/stenlid/dieback-of-european-ash.pdf (accessed on 31 August 2021).

17. Menkis, A.; Bakys, R.; Åslund, M.S.; Davydenko, K.; Elfstrand, M.; Stenlid, J.; Vasaitis, R. Identifying Fraxinus excelsior tolerant to ash dieback: visual field monitoring versus a molecular marker. Forest Pathology 2019, 00:e12572. (DOI: 10.1111/efp.12572)

18. Enderle, R.; Stenlid, J.; Vasaitis, R. An overview of ash (Fraxinus spp.) and ash dieback disease in Europe. CAB Reviews 2019, 14:025. (DOI : 10.1079/PAVSNNR201914025) 
19. Semizer-Cuming, D.; Krutovsky, K.V.; Baranchikov, Yu.N.; Kjær, E.D.; Williamset, S.G. Saving the world's ash forests calls for international cooperation now. Nature Ecology E Evolution 2019, 3, 141-144. (DOI: 10.1038/s41559-018-0761-6)

20. McKinney, L.V.; Nielsen L.R.; Collinge, D.B.; Thomsen, I/M/; Hansen, J.K.; Kjær, E.D. The ash dieback crisis: genetic variation in resistance can prove a long-term solution. Plant Pathology 2014, 63 (3), 485-499 (DOI: 10.1111/ppa.12196) 